\title{
Determinação da eficiência de campo de conjuntos de máquinas convencionais de preparo do solo, semeadura e cultivo ${ }^{1}$
}

\author{
Gastão M. da Silveira ${ }^{2}$, Kyoshi Yanai $^{2}$ \& Sergio A. H. Kurachi ${ }^{2}$
}

\begin{abstract}
RESUMO
A lucratividade de qualquer propriedade agrícola ou de determinada cultura, depende de um gerenciamento correto dos trabalhos executados. Por isso, naquelas mecanizadas, a monitoração do trabalho realizado pelas máquinas e pelos implementos agrícolas sempre mereceu grande atenção. Neste trabalho, utilizou-se um sistema automático de aquisição de dados para o levantamento de informações de campo, com o objetivo de se determinar a capacidade de trabalho e eficiência de campo de máquinas e implementos usados nas operações convencionais de aração, gradeação, semeadura e cultivo da cultura de milho. Este sistema foi concebido para obtenção de dados da localização do trator no campo, através de sistema de posicionamento global (GPS), do consumo de combustível e da velocidade de deslocamento. O conjunto de dados, que pode ser obtido repetidamente, permite o controle estatístico dos parâmetros operacionais, gerando relatórios contendo os principais indicadores gerenciais como rendimento operacional, e as condições de trabalho. Experimentos foram realizados no Centro APTA de Engenharia e Automação do IAC/SAA.
\end{abstract}

Palavras-chave: rendimento operacional, operações agrícolas convencionais, capacidade de trabalho

\section{Field efficiency determination of set of conventional machines of plowing, seeding and cultivation}

\begin{abstract}
The profitability of any farm or of a certain crop depends on the adequate management of the tasks executed. For that, in mechanized farms, the careful controlling of agricultural machine and implements, always, deserved a great attention. In this paper, an automatic system of data acquisition, designed for field information survey, was used. The obtained data are related with time and motion, work capacity and field efficiency. The system was conceived for determining the position of the tractor in the field by means of global positioning system (GPS), the fuel comsuption and forward tractor velocity. This set of data makes the control of the operational parameters possible, generating reports containing the most important management indicators such as operational yield and the work conditions. Machinery productivity measurements were carried out in corn fields of the Automation and Agricultural Engineering Center of IAC/SAA. Conventional plowing, harrowing, seeding and mechanical weed control operations were monitored, aiming to characterize performance characterization of the machinery used.
\end{abstract}

Key words: machinery productivity measurement, operational yield, conventional agricultural operations, work capacity

1 Trabalho financiado pela Fundação de Amparo à Pesquisa do Estado de São Paulo.

${ }^{2}$ Centro APTA. de Engenharia e Automação, IAC/SAA, Rod. D. Gabriel PB Couto, Km 65, CP 26 CEP 13201-970, Jundiaí, SP. Fone (011) 4582-8155 Ramal

137. E-mail: silveira@iac.sp.gov.br., yanai@iac.sp.gov.br, kurachi@iac.sp.gov.br 


\section{INTRODUÇÃO}

Segundo Deere \& Company (1975), o gerenciamento de maquinaria tem-se tornado cada vez mais importante na execução de operações agrícolas, por estar diretamente relacionado com a capacidade de combinar terra, trabalho e capital para a obtenção de um retorno que signifique lucro satisfatório. Os custos da maquinaria em relação aos custos totais da exploração de uma fazenda, normalmente indicam se a sua utilização está sendo feita de forma acertada ou não.

As máquinas deverão estar corretamente adequadas ao tamanho da fazenda e às operações a serem realizadas, de modo que no final resulte numa combinação de equipamentos a mais econômica possível. A maquinaria selecionada deve ter capacidade satisfatória para completar todas as operações dentro dos períodos críticos de tempo disponíveis. Com a produção continuada de máquinas cada vez maiores e mais caras, cada unidade comprada representa despesas também substancialmente maiores.

Máquinas usadas em conjunto deverão ser adequadas umas às outras; por exemplo, um trator deverá ser capaz de fornecer a quantidade exata de potência para puxar ou acionar toda a gama de implementos ou máquinas selecionadas para o trabalho em combinação, na melhor velocidade de operação possível. Deste modo, a capacidade de trabalho da máquina, a eficiência de campo e os requisitos de potência, são fatores fundamentais no gerenciamento da utilização da maquinaria agrícola.

O estudo das operações agrícolas, levando-se em conta a capacidade de trabalho e a eficiência de campo, visa racionalizar o emprego das máquinas, implementos e ferramentas na execução dos trabalhos. Dá-se o nome de desempenho operacional a um complexo conjunto de informações que definem, em termos quali-quantitativos, os atributos da maquinaria agrícola quando executam operações sob determinadas condições (Folle \& Franz 1990).

Segundo ASAE (1999), Cañavate \& Hernanz (1989), Corrêa (1967), Folle \& Franz (1990), Leite (1972), Mantovani (1987), Witney (1988) e Molin \& Milan (2002) a capacidade de campo de uma máquina vem a ser a quantidade de trabalho produzida na unidade de tempo. A capacidade de campo pode ser efetiva e teórica.

Para Hunt (1974) a eficiência de campo é igual à eficiência de tempo, definida como a razão entre o tempo efetivamente usado e o tempo total disponível, quando são consideradas apenas as operações executadas dentro de campo cultivado.

De outro lado, a capacidade teórica de campo $\left(\mathrm{C}_{\mathrm{t}}\right)$ é o valor de desempenho obtido se a máquina trabalhasse 100\% do tempo, na velocidade ideal para operação, utilizando 100\% de sua largura teórica de trabalho (ASAE, 1996b).

De acordo com Smith (1965), os fatores seguintes influem na eficiência de campo de uma máquina agrícola: o método de operação ou padrão de operação no campo; o formato do campo; o tamanho do campo; a capacidade teórica de operação; as condições umidade e da cultura; a produção do campo na época da colheita e as limitações dos sis- temas, razão por que, eficiências de campo não são valores constantes para máquinas específicas mas são muito variáveis.

Para Richey et al. (1961) a capacidade de trabalho ou de campo das máquinas agrícolas é função dos seguintes fatores: a) largura de trabalho da máquina, que pode ser afetada pela largura medida da máquina e pela porcentagem da largura da máquina realmente usada; b) velocidade de deslocamento, que pode ser afetada pela exigência de potência da máquina tracionada; potência fornecida pela unidade tratora; resistência ao rolamento; inclinação do terreno; qualidade do trabalho; rugosidade do terreno; obstáculos, etc.; c) porcentagem de tempo parado ou não operado devido ao tempo gasto em translados para ou dentro do terreno a ser trabalhado; tempo gasto em viragens ou manobras nas extremidades do campo; abastecimento das máquinas, por exemplo, semeadoras e/ou adubadoras; descarregamento de produtos colhidos; lubrificação e reabastecimento de combustível; ajuste ou regulagem das máquinas; afiação das ferramentas de corte durante a execução da operação; reposição das partes desgastadas; embuchamentos, quebras etc. Desses fatores, a porcentagem do tempo de paradas é a mais difícil de se avaliar.

O objetivo do trabalho realizado foi o de monitorar as atividades de mecanização, abrangendo as operações convencionais de: aração, gradeação, semeadura e cultivo, determinando-se as capacidades e a eficiência de campo dos diferentes conjuntos trator/implemento, de pequeno porte, usados na implantação de milharais, em áreas do Centro de Engenharia e Automação do IAC, em Jundiaí; para isto, utilizouse um sistema automático de aquisição de dados, descrito por Silveira et al. (2003), que permitiu uma avaliação da eficiência operacional das máquinas usadas; além disso, o consumo de combustível foi determinado durante a execução dos experimentos realizados.

\section{MATERIAL E MÉTODOS}

O sistema automático de aquisição de dados, acima citado, possui uma unidade de aquisição de dados (UA) que monitora os sensores (GPS, consumo de combustível), e filtra os dados antes de serem armazenados na memória de bordo. Por meio de um relógio interno, associa a informação à data e a hora de sua obtenção.

Um receptor GPS, marca Ashtech Magellan, modelo G-8 e um sensor de consumo de combustível, marca Oval, tipo M-III modelo LSF41L8-M2, foram instalados em um trator marca Massey Ferguson, modelo 65X, motor marca Perkins, modelo AD4-203 com 4 cilindros e 48,8 kW de potência a 2200 rpm. O receptor GPS determina a posição do trator e, com a posição atual e anterior e o tempo entre elas, calculase a velocidade do conjunto. Sua acurácia é de $10 \mathrm{~m}$, dada pelo valor médio quadrático, enquanto as leituras são feitas a cada 10 segundos e armazenadas na UA.

Para se coletar, organizar e tratar os dados de campo, utiliza-se um sistema com três módulos. O módulo de comunicação recupera os dados da unidade de aquisição via cabo, 
por meio do protocolo serial RS232; o módulo de administração do banco de dados organiza os registros das diferentes operações e gera um relatório operacional com os principais indicadores gerenciais, que inclui código do registro, data, hora de início, hora de término, duração, tempo total, tempo morto, tempo efetivo, consumo de combustível, capacidade teórica de trabalho, capacidade efetiva de trabalho, eficiência, operação, local da operação, gleba, implemento, largura do implemento, velocidade média do GPS, trator, tratorista, cultura, solo, rota, arquivo DAT, TXT do GPS, sensores e erro, enquanto o terceiro módulo, chamado Geodata, permite a conversão de dados para que estes possam ser manipulados em planilhas de cálculo de sistemas de informação geográfica.

Para o estudo da eficiência operacional foram considerados, no Banco de Dados, os seguintes itens: número do registro, tempo morto, tempo efetivo de trabalho, consumo $\left(\mathrm{L} \mathrm{h}^{-1}\right)$, capacidade teórica de trabalho $\left(\mathrm{ha} \mathrm{h}^{-1}\right)$, capacidade efetiva de trabalho (ha $\mathrm{h}^{-1}$ ) e eficiência (\%). Para o cálculo, usou-se o programa Microsoft Excel 2000.

Considerou-se tempo morto aquele perdido em manobras, ajustes, regulagem etc. e, como tempo efetivo de trabalho, aquele realmente gasto na execução da tarefa, no campo.

No campo foram usados os seguintes implementos, acoplados ao sistema hidráulico de levante por três pontos do trator: a) arado marca Massey Ferguson de 3 discos com 30" de diâmetro, largura média de trabalho de $0,80 \mathrm{~m}$, profundidade média de trabalho de $0,23 \mathrm{~m}$, velocidade média de deslocamento do trator de $3,513 \mathrm{~km} \mathrm{~h}^{-1}$, em terceira marcha reduzida; b) grade marca Baldan com 28 discos de 18" de diâmetro, largura média de corte de 2,63 m, profundidade média de trabalho de $0,20 \mathrm{~m}$, velocidade média de deslocamento do trator de $5,460 \mathrm{~km} \mathrm{~h}^{-1}$, em primeira marcha simples, nas três gradeações, realizadas duas após a aração e uma antes da semeadura; c) semeadora-adubadora de duas linhas marca Marchesan, largura média de trabalho de $1 \mathrm{~m}$, velocidade média de deslocamento do trator de 3,440 $\mathrm{km} \mathrm{h}^{-1}$, em terceira marcha reduzida e d) cultivador de quatro linhas marca Massey Ferguson, largura média de trabalho de $3 \mathrm{~m}$, velocidade média de deslocamento do trator de 3,526 $\mathrm{km} \mathrm{h}^{-1}$, em terceira marcha reduzida.

Para os cálculos da capacidade efetiva de campo $\left(\mathrm{C}_{\mathrm{ef}}\right)$ utilizou-se a mesma equação adotada por diversos autores, ASAE (1999), Cañavate \& Hernanz (1989), Correa (1967), Folle \& Franz (1990), Leite (1972), Mantovani (1987), Witney (1988) e Molin \& Milan (2002):

$$
\mathrm{C}_{\mathrm{ef}}=\mathrm{V} \times \mathrm{L} \text { x e } / 10
$$

donde:

$\mathrm{C}_{\text {ef. }} \quad$ - capacidade efetiva de campo ha $\mathrm{h}^{-1}$

$\mathrm{V}$ - velocidade de operação em, $\mathrm{km} \mathrm{h}^{-1}$

L - largura de trabalho da máquina da maquina, m

10 - constante

e - eficiência de campo, expressa em decimal

Nesta equação, o fator mais crítico é a eficiência de campo (e), definida como a razão entre a capacidade efetivamente obtida em campo, em dado tempo e aquela que se- ria obtida considerando-se o tempo total em que a máquina esteve no campo.

A eficiência de campo ou tempo foi calculada conforme definição de (Hunt, 1974) e a capacidade teórica $\left(\mathrm{C}_{\mathrm{t}}\right)$ de acordo com a ASAE (1996)

\section{RESULTADOS E DISCUSSÃO}

Na Tabela 1 são apresentados os resultados das diversas determinações de capacidade de trabalho e eficiência de campo, realizadas com diferentes conjuntos de trator/máquina agrícola convencional, usados na implantação de cultura de milho, no C.de Mecanização e Automação/IACJundiaí.

A eficiência média de campo ou de tempo do conjunto trator/arado de disco foi de 66,0\%, aproximadamente (Tabela 1). Durante a aração verificou-se pouca variação de velocidade de operação do conjunto trator/arado, nas diversas glebas trabalhadas.

Quanto ao conjunto trator/grade de disco, a eficiência média de campo foi de 62,1\% (Tabela 1); neste caso, a velocidade de operação medida nas diversas glebas gradeadas variou muito; a menor velocidade média foi de 3,800 $\mathrm{km} \mathrm{h}^{-1} \mathrm{e}$ a maior de $6,510 \mathrm{~km} \mathrm{~h}^{-1}$, com coeficiente de variação (C.V.) de 20,4\%; esta variação se deve ao fato de que, na primeira gradeação após a aração, o solo estava muito seco, duro e com torrões em grande quantidade.

No caso da semeadura, a eficiência média do conjunto trator/semeadora foi de 49,2\%. A velocidade média de operação foi de 3,440 $\mathrm{km} \mathrm{h}^{-1}$, com valor mínimo de 2,900 $\mathrm{km} \mathrm{h}^{-1}$; máximo de 4,460 $\mathrm{km} \mathrm{h}^{-1}$ e CV de 20,4\%, (Tabela 1). A velocidade de operação variou bastante e as diferenças foram devidas às diferentes condições de solo durante a semeadura.

Em se tratando do conjunto trator/cultivador, a eficiência média determinada foi de $60,52 \%$ e a velocidade média de operação foi de $3,526 \mathrm{~km} \mathrm{~h}^{-1}$, com valor mínimo de $2,730 \mathrm{~km} \mathrm{~h}^{-1}$ e máximo de $3,83 \mathrm{~km} \mathrm{~h}^{-1}$ (Tabela 1). A variação da velocidade de operação foi menor que as verificadas nas operações de gradeação e semeadura.

As condições do solo influíram principalmente na eficiência das operações de gradeação e de semeadura. A grande quantidade de torrões resultante da aração e o solo inicialmente ressecado, prejudicaram o trabalho posterior de gradeação, que foi realizado em três etapas; posteriormente, na época da semeadura, com a umidade do solo mais alta, interrupções freqüentes foram ocasionadas no trabalho executado pela semeadora, em razão de entupimentos causados pela terra molhada na saída dos seus tubos de descarga. Os diferentes tamanhos de gleba utilizados também devem ter influído na baixa eficiência das operações realizadas. Em alguns casos, os tempos efetivos de trabalho foram menores ou iguais aos tempos mortos registrados, ocasionando baixos rendimentos do trabalho realizado.

A velocidade efetiva de trabalho das máquinas utilizadas Tabela 2 ficou muito aquém daquela citada como típica pela ASAE (1996a). Ela foi a máxima possível de se utilizar dentro das restrições impostas pelas condições de 
Tabela 1. Resultados de determinações de rendimento de trabalho obtidos com diferentes conjuntos de máquinas agrícolas convencionais

\begin{tabular}{|c|c|c|c|c|c|c|c|c|}
\hline \multicolumn{9}{|l|}{ 1. ARAÇÃO } \\
\hline $\begin{array}{l}\text { Código de registro } \\
\text { da área arada }\end{array}$ & $\begin{array}{l}\text { Tempo morto } \\
\text { total (h) }\end{array}$ & $\begin{array}{l}\text { Tempo efetivo } \\
\text { de trabalho (h) }\end{array}$ & $\begin{array}{l}\text { Consumo de } \\
\text { combustivel }\left(L \mathrm{~h}^{-1}\right)\end{array}$ & $\begin{array}{c}\text { Capacidade teórica } \\
\left(\mathrm{ha} \mathrm{h}^{-1}\right)\end{array}$ & $\begin{array}{l}\text { Capacidade } \\
\text { efetiva }\left(h a h^{-1}\right)\end{array}$ & Eficiência (\%) & $\begin{array}{l}\text { Velocidade efetiva } \\
\text { de trabalho } \\
\left(\mathrm{km} \mathrm{h}^{-1}\right)\end{array}$ & $\begin{array}{c}\text { Largura } \\
\text { de trabalho }(m)\end{array}$ \\
\hline 270 & 00:20:02 & 01:22:53 & 4,26 & 0,304 & 0,244 & 80,53 & 3,800 & 0,80 \\
\hline 273 & 00:50:04 & 02:59:31 & 4,12 & 0,269 & 0,210 & 78,19 & 3,370 & 0,80 \\
\hline 276 & $00: 21: 55$ & 00:28:25 & 4,16 & 0,269 & 0,152 & 56,46 & 3,370 & 0,80 \\
\hline 277 & 00:16:21 & 00:15:34 & 3,44 & 0,280 & 0,136 & 48,77 & 3,510 & 0,80 \\
\hline Média geral & & & 3,995 & 0,281 & 0,186 & 65,98 & 3,513 & 0,80 \\
\hline C.V. & & & 9,4 & 5,9 & 27,1 & 23,9 & 5,8 & \\
\hline \multicolumn{9}{|l|}{ 2. GRADEAÇÃO } \\
\hline 271 & $00: 24: 25$ & 00:30:57 & 5,40 & 1,201 & 0,671 & 55,90 & 4,570 & 2,63 \\
\hline 272 & 00:21:28 & 00:47:11 & 3,93 & 1,293 & 0,889 & 68,73 & 4,920 & 2,63 \\
\hline 274 & 00:15:42 & $00: 40: 21$ & 4,86 & 1,375 & 0,990 & 71,99 & 5,230 & 2,63 \\
\hline 275 & 00:12:22 & 00:35:19 & 4.10 & 1,591 & 1,178 & 74,07 & 6,050 & 2,63 \\
\hline 278 & 00:08:08 & 00:09:51 & 4,72 & 1,293 & 0,708 & 54,77 & 4,920 & 2,63 \\
\hline 279 & 00:07:19 & $00: 10: 41$ & 5,00 & 1,480 & 0,878 & 59,35 & 5,630 & 2,63 \\
\hline 280 & 00:04:45 & 00:03:11 & 4,64 & 1,417 & 0,568 & 40,13 & 5,390 & 2,63 \\
\hline 281 & 00:03:50 & 00:02:37 & 4,55 & 1,712 & 0,694 & 40,57 & 6,510 & 2,63 \\
\hline 282 & 00:11:05 & 00:33:48 & 4,99 & 1,685 & 1,269 & 75,31 & 6,410 & 2,63 \\
\hline 283 & 00:10:43 & 00:24:42 & 3,82 & 0,999 & 0,696 & 69,74 & 3,80 & 2,63 \\
\hline 284 & 00:04:41 & 00:10:13 & 4,69 & 1,435 & 0,984 & 68,57 & 5,460 & 2,63 \\
\hline 285 & 00:01:50 & 00:03:37 & 4,66 & 1,304 & 0,865 & 66,36 & 4,960 & 2,63 \\
\hline Média geral & & & 4,61 & 1,399 & 0,866 & 62,12 & 5,320 & 2,63 \\
\hline C.V. & & & 8,8 & 14,6 & 27,3 & 6,1 & 20,4 & \\
\hline \multicolumn{9}{|l|}{ 3. SEMEADURA } \\
\hline 286 & 00:51:15 & 00:20:52 & 2.99 & 0,332 & 0,206 & 62,33 & 3,32 & 1,00 \\
\hline 287 & 00:11:15 & 00:34:22 & 3.05 & 0,446 & 0,198 & 44,40 & 4,46 & 1,00 \\
\hline 288 & 00:31:47 & & 2.75 & 0,308 & 0,122 & 39,63 & 3,08 & 1,00 \\
\hline 289 & 00:33:53 & & 2.83 & 0,29 & 0,146 & 50,35 & 2,9 & 1,00 \\
\hline Média geral & & & 2,905 & 0,344 & 0,168 & 49,178 & 3,440 & 1,00 \\
\hline C.V. & & & 4,8 & 20,4 & 24,2 & 19,9 & 20,4 & \\
\hline \multicolumn{9}{|l|}{ 4. CULTIVO } \\
\hline 308 & 00:21:04 & 00:55:05 & 4.56 & 1,149 & 0,831 & 72,34 & 3,83 & 3,00 \\
\hline 309 & 00:21:05 & 00:56:54 & 4.44 & 1,116 & 0,814 & 72,96 & 3,72 & 3,00 \\
\hline 310 & 00:20:04 & 00:20:28 & 4.03 & 0,819 & 0,413 & 50,49 & 2,73 & 3,00 \\
\hline 311 & 00:12:03 & 00:21:35 & 4.06 & 1,119 & 0,718 & 64,17 & 3,73 & 3,00 \\
\hline 312 & 00:11:08 & 00:08:16 & 3.97 & 1,086 & 0,462 & 42,61 & 3,62 & 3,00 \\
\hline Média geral & & & 4,212 & 1,058 & 0,648 & 60,514 & 3,526 & 3,00 \\
\hline C.V. & & & 6,4 & 12,8 & 30,5 & 22,3 & 12,8 & \\
\hline
\end{tabular}

trabalho existentes, inclusive as próprias máquinas, além de uma das maiores causas das baixas eficiências registradas. As operações de aração, semeadura e de cultivo, só puderam ser realizadas com o trator operando em $3^{\mathrm{a}}$ marcha reduzida; apenas na gradeação foi possível trabalharse com uma marcha mais veloz, a $1^{\text {a }}$ simples, em razão da maneira como a gradeação foi realizada, com a máquina executando passadas parcialmente sobrepostas, na primeira operação logo após a aração e, nas operações seguintes, com o solo em melhores condições de trabalho.

As eficiências médias de trabalho obtidas em todas as operações realizadas, ficaram também abaixo daquelas relatadas por diversos autores (Tabela 2).

Com relação ao consumo de combustível, os valores médios registrados nas diferentes operações realizadas foram: 3,995 L h-1 na aração; 4,610 L h h-1 na gradeação; 2,905 L h'-1 na semeadura e 4,212 $\mathrm{L} \mathrm{h}^{-1}$ no cultivo.

Com o sistema automático e leituras realizadas a intervalos de 10 s, registraram-se, em 1 h de operação, 360 dados por sensor de medição utilizado, por exemplo, no caso da operação de aração monitorada, com o conjunto trator/máquina agrícola se deslocando a velocidade média de $3,516 \mathrm{~km} \mathrm{~h}^{-1}$, equivaleria a uma coleta de dados a cada 9,75 m de distância efetiva de execução do citado trabalho de preparo do solo. Deste modo, o número total de dados adquirido e processado pelo sistema ao final de um dia de trabalho, é mais que suficiente para assegurar valores médios confiáveis para serem utilizados nos cálculos da eficiência de campo de uma máquina agrícola.

Na Tabela 2, apresentada a seguir, foram reunidos dados de eficiência de campo, obtidos por diversos autores, em determinações semelhantes. 
Tabela 2. Valores de eficiência de campo citados na literatura consultada

\begin{tabular}{|c|c|}
\hline \multicolumn{2}{|l|}{ 1. Aração } \\
\hline ASAE (1996a) & $\begin{array}{l}70 \text { a } 90 \% \text { (arado de aiveca), valor típico } \\
\text { de } 85 \% \text { e amplitude de velocidade de } 5 \text { a } \\
10 \mathrm{~km} \mathrm{~h}^{-1} \text {, valor típico de } 7 \mathrm{~km} \mathrm{~h}^{-1}\end{array}$ \\
\hline Corrêa (1967) e Mantovani (1987) & 70 a $85 \%$ \\
\hline Deere \& Company (1975) & 77 a $90 \%$ \\
\hline $\begin{array}{l}\text { Folle \& Franz (1990) e Molin \& Milan } \\
(2002)\end{array}$ & 70 a $90 \%$ \\
\hline Leite (1972) e Silveira (2001) & 75 a $90 \%$ \\
\hline Witney (1988) & 75 a $85 \%$ \\
\hline \multicolumn{2}{|l|}{ 2. Gradeação } \\
\hline ASAE (1996a) & $\begin{array}{l}70 \text { a } 90 \% \text {, valor típico de } 85 \% \text { e amplitude } \\
\text { de velocidade de } 6,5 \text { a } 11 \mathrm{~km} \mathrm{~h}^{-1} \text {, valor } \\
\text { típico de } 10 \mathrm{~km} \mathrm{~h}^{-1}\end{array}$ \\
\hline Corrêa (1967) e Mantovani (1987) & 70 a $90 \%$ \\
\hline Deere \& Company (1975) & 77 a $90 \%$ \\
\hline $\begin{array}{l}\text { Folle \& Franz (1990) e Molin \& Milan } \\
\text { (2002) }\end{array}$ & 70 a $90 \%$ \\
\hline Leite (1972) e Silveira (2001) & 75 a $90 \%$ \\
\hline Witney (1988) & 80 a $90 \%$ \\
\hline \multicolumn{2}{|l|}{ 3. Semeadura } \\
\hline ASAE (1996) & $\begin{array}{l}50 \text { a } 75 \% \text { (semeadora de precisão), valor } \\
\text { típico de } 65 \% \text { e amplitude de velocidade } \\
\text { de } 6,5 \text { a } 11 \mathrm{~km} \mathrm{~h}^{-1} \text {, velocidade típica de } \\
9 \mathrm{~km} \mathrm{~h}^{-1}\end{array}$ \\
\hline Corrêa (1967) e Mantovani (1987) & 70 a $85 \%$ \\
\hline Deere \& Company (1975) & 45 a $65 \%$ \\
\hline $\begin{array}{l}\text { Folle \& Franz (1990) e Molin \& Milan } \\
\text { (2002) }\end{array}$ & 65 a $85 \%$ \\
\hline Leite (1972) e Silveira (2001) & 60 a $80 \%$ \\
\hline Witney (1988) & 60 a $70 \%$ \\
\hline \multicolumn{2}{|c|}{ 4. Cultivo em culturas de linhas espaçadas } \\
\hline ASAE (1996) & $\begin{array}{l}70 \text { a } 90 \% \text {, valor típico de } 80 \% \text { e amplitude } \\
\text { de velocidade de } 5 \text { a } 11 \mathrm{~km} \mathrm{~h}^{-1} \text {, velocidade } \\
\text { típica de } 8 \mathrm{~km} \mathrm{~h}^{-1}\end{array}$ \\
\hline Corrêa (1967) e Mantovani (1987) & 75 a $90 \%$ \\
\hline Deere \& Company (1975) & 65 a $80 \%$ \\
\hline Leite (1972) e Silveira (2001) & 75 a $90 \%$ \\
\hline
\end{tabular}

\section{CONCLUSÕES}

1. A eficiência média obtida nas determinações realizadas durante a execução das operações de aração, gradeação, semeadura e cultivo na cultura do milho, foi considerada baixa.

2. As velocidades de trabalho das máquinas usadas ficaram muito aquém daquelas citadas na literatura

3. O sistema automático permite a obtenção de um histórico para caracterização das operações mecanizadas, podendo, em geral, fazer parte do instrumental do trator e ser utilizado permanentemente na aquisição e processamento de dados que possibilitem um gerenciamento efetivo das diversas atividades relacionadas com o desempenho das máquinas agrícolas.

\section{LITERATURA CITADA}

ASAE Standards. ASAE D497.4 Agricultural machinery management data. American Society of Agricultural Engineers, St. Joseph, 1996a. p.359-368. (NAO LISTADO).

ASAE Standards ASAE S495 DEC94 Uniform terminology for agricultural machinery management. American Society of Agricultural Engineers, St. Joseph,1996b. p.324-25.

ASAE Standards. ASAE D497.2 Agricultural machinery management data. American Society of Agricultural Engineers, St. Joseph, 1999. p.332-339.

Cañavate, J. O.; Hernanz, J. L. Tecnica de la mecanizacion agraria 3. ed. Madrid: Mundi Prensa, 1989. 643p.

Corrêa, A. A. M. Rendimento e despesas no emprego de tratores e implementos agrícolas. Rio de Janeiro: Ministério da Agricultura, Serviço de Informação Agrícola. 1967. 61p.

Deere \& Company. Measuring machine capacity. In FMO - Fundamentals of Machine Operation: Machinery Management. Moline, Illinois. 1975. Chapter 2, 28p.

Folle, S.; Franz, C. A. B. Trator agrícola: características e fundamentos para sua seleção. Planaltina: Empresa Brasileira de Pesquisa Agropecuária - EMBRAPA. 1990. 24p.

Hunt, D. Machine performance. In Farm Power and Machinery Management. Ames, Iowa. Iowa State University Press. 1974. Chapter 1, p. 5.

Leite, H. F. Guia de mecanização rural - Coopercotia. São Paulo: Edecê 1972. 178p.

Mantovani, E.C. Seleção de equipamentos agrícolas. In: Curso Planejamento da mecanização para pequenos e médios estabelecimentos. Santa Catarina: EMATER, 1987 p.26-27.

Molin, J. P.; Milan, M. Trator-implemento: dimensionamento. Capacidade operacional e custo.In: Gonçalves, J. L. M.; Stape, J. L. (ed.) Conservação e cultivo de solos para plantações florestais. Piracicaba: Instituto de Pesquisas Florestais, 2002. p. 409-436.

Richey, C. B.; Jacobson, P.; \& Hall, C. A. Economics of farm machinery. In: Agricultural engineers' handbook. New York: McGraw-Hill Book Company, 1961, Chapter 1, p.1-17.

Silveira, G. M. Os cuidados com o trator. 1.ed., Viçosa: Aprenda Fácil Editora, 2001. 309p.

Silveira, G. M.; Storino, M.; Peche Filho A.; Yanai, K.; Bernardi J. A. Sistema de aquisição automática de dados para o gerenciamento da mecanização agrícola e agricultura de precisão. In: Congresso Brasileiro de Informática, 4, 2003, Porto Seguro. Anais... Porto Seguro: SBIAAA, 2003. v.1 p.1-5.

Smith, H. P. Economics and management of farm equipment. In Farm Machinery and Equipment. New York: McGraw-Hill Book Co. 1965. Chapter 26, 473p

Witney, B. D. Choosing and using farm machines. Edinburgh: Land Technology 1988. 412p. 